Article

\title{
Sustainability Living Labs as a Methodological Approach to Research on the Cultural Drivers of Sustainable Development
}

\author{
Grzegorz Baran (1) and Aleksandra Berkowicz *(1) \\ Faculty of Management and Social Communication, Jagiellonian University, 30-348 Cracow, Poland; \\ g.baran@uj.edu.pl \\ * Correspondence: aleksandra.zurowska@uj.edu.pl
}

Received: 15 May 2020; Accepted: 10 June 2020; Published: 13 June 2020

check for updates

\begin{abstract}
Given that culture-driven processes cannot be researched and designed if taken out from the real-life environment, an appropriate methodology to study the impact of culture on sustainable development is needed. The aim of the research was to develop a model of a sustainability living lab as a methodological approach based on the living lab concept and its capabilities to study the cultural drivers of sustainable development. The research was carried out with use of the conceptual research framework based on analyzing existing knowledge on cognitive processes within living laboratories and their interpretation in the light of the relationship between culture and sustainable development. First, the results of the analysis of sustainability cultural drivers and the living lab concept are presented, which constitute the research framework of the study. Then, the main contribution as a novel theoretical concept of sustainability living lab is elaborated and discussed. The novelty of this approach to research on the cultural drivers of sustainable development is based on linking together in a coherent model the consequences of the dual nature of culture and the arguments for conducting such research beyond the limitations of closed laboratories towards the highly dynamic environment of real life.
\end{abstract}

Keywords: cultural drivers; living labs; sustainable development

\section{Introduction}

The existence, implementation and development of the concept of sustainable development are primarily determined by cultural factors. "In its simplest form, the concept of sustainability embodies a desire that future generations inherit a world at least as bountiful as the one we inhabit. However, how to get there, as is demonstrated above, will always be the subject of constant debate. This debate is about values; it is a cultural debate" [1]. Culture is the foundation of the three pillars of sustainable development: economic, ecological and social. There are a number of studies on the economic or ecological dimension, while for culture there are no guidelines for assessing the cultural impact of sustainable development or the dynamics of cultural development, except for beginnings in the field of cultural heritage [2]. Similarly to culture, neglected dimensions related to the concept of sustainable development are: assets (or technical) and governance aspects. They are necessary as a framework for measuring sustainable development [3].

The transformative power of culture is reflected not only in human development, but also affects the environment in which man functions. Culture plays an instrumental role in relation to economic development. Culture can be a powerful driver for development. This is influenced by, among other things, cultural heritage and cultural industry, not only as a source of income, but also by changing the image of a given region and engaging the workforce. In the social dimension, culture helps to 
build social cohesion and interpersonal dialogue and strengthens and shapes the values of society [4]. Culture affects the attitudes and behavior of people towards the natural environment, and in particular imposes a moral obligation, which is responsibility for nature and its resources.

Culture has another key dimension: governance. It refers to the ways in which institutions function, processes and, above all, the relationship between the state and citizens and other entities [5]. In addition, culture through its innovation potential can help solve problems, including challenges related to sustainable development.

This research study is aimed at developing a model of a sustainability living lab, considered as a methodology based on the concept of living labs seen from the perspective of its capabilities to study the impact of cultural factors on sustainable development. This model is constituted on the processes of inquiry into the role of cultural drivers occurring within living labs considered as socio-technical infrastructure for sustainable innovations to emerge in real-life settings. These laboratories are seen as real-life ecosystems for inquiry processes that lead to creating and experimenting with sustainable development ideas and converting them into solutions to social problems. This paper presents the conceptual phase of the undertaken considerations, which leads to the outline of such processes within a broader conceptual framework based on the living lab concept.

The choice of the research problem resulted from the research gap identified in the literature study. The literature review proved the significant lack of research studies on the methodology for the research on the impact of cultural factors on sustainable development, especially on the cultural drivers of developing sustainable innovation, including the lack of research on the potential use of living laboratories in which such innovations could be researched and designed with and by potential users in real-life contexts.

The contribution of this paper is based on the proposed model of a sustainability living lab that provides a novel methodological approach to research on the cultural drivers of sustainable development. This approach takes into account both (1) the undervalued dual nature of culture and (2) that social practices are tailored to their setting, which means that the research needs to extend beyond the limitations of closed laboratories towards the highly dynamic environment of real life. The novelty of this approach is based on linking together in a coherent model both these aspects that cause difficulties and limitations in research on the cultural drivers of sustainable development.

The duality of culture means that on the one hand, it provides a pool of resources for action, through which it determines and enables action at all. On the other hand, culture itself is determined and transformed by the actions of social actors. This causes the limitations in research on the cultural drivers of sustainable development (regarding actions and practices for sustainable development) if they are conducted in isolation from the real-life context. This context is not only included in the proposed model, but the research processes themselves are immersed in real-life settings by adopting the assumptions of the concept of a living lab. Hence, the proposed model would be a valuable approach to research on the reciprocal impact of the cultural context and the sphere of social actions and practices in real-life situations that can be conducted within the highly dynamic environment of real life.

After this introduction, the paper proceeds as follows. Section 2 contains a review of previous work undertaken in the area of the impact of cultural factors on sustainable development and the concept of living labs as the research framework in this study. Then, the research method is presented and explained in Section 3. Section 4 contains the research results and achievements, where the theoretical model of sustainability living lab is presented. The results are discussed in Section 5, where the theoretical nature of the study and the broad context of the relationship between culture and sustainable development, and the possibilities of their study, are taken into account. The limitations of the proposed model and future research directions are also discussed in this section. Section 6 offers some concluding thoughts and suggestions for future research. 


\section{Theoretical Background}

The fundamental context of the undertaken research includes: the state of knowledge on the impact of cultural factors on sustainable development and the concept of living labs studied as a methodology that can facilitate the research on the cultural drivers of sustainable development.

\subsection{The Cultural Drivers}

The impact of cultural drivers on sustainable development should be started by defining these two key concepts: culture and sustainable development. There are many different definitions of culture. Modern theorists of culture have pointed out that the concept of culture is very complex and used in various ways. For the purposes of this article, two approaches were chosen: systemic and anthropological and sociological.

In systemic terms, three aspects of culture should be distinguished [6] (p. 52):

- Culture as an activity, i.e., as a rationalization and humanization of the world,

- Culture as a product, or "sum" of human works,

- Culture as a quality (perfection) of the human spirit.

The specified elements are characterized by cultural dynamism - they interpenetrate and complement each other, which means that they are integrally connected with each other, they allow us to distinguish spiritual culture and material culture, individual and social culture, i.e., civilization, the method (system) of social life [6]. In the anthropological and sociological sense, culture is "a relatively integrated whole, covering people's behavior following patterns common to social community, developed and assimilated in the course of interaction, and containing products of such behavior" [7] (p. 38).

The concept of sustainable development is ambiguous and general. The origins of the idea of sustainable development are attributed to the 18th-century high-ranking official of Augustus the Strong-Hans Carl von Carlowitz. He conceived of equilibrium as the equality between the number of trees planted and felled. In this way, he opposed the forest robbery, which he viewed as violating the rule of caring for wood [8]. Although the idea of sustainability was primarily intended to immunize the economic system against crises [8], this "care for proper forestry management" - more or less realized at that time - was a manifestation of environmental protection also including culture.

The idea of sustainable development has been popularized thanks to the report of the United Nations' World Commission on Environment and Development, called the Brundtland Report. The official name of this document, published in 1987, is Our common future. It defines sustainable development as "meeting the needs of the present without compromising the ability of future generations to meet their own needs... A process of change in which the exploitation of resources, the direction of investments, the orientation of technological development, and institutional change are all in harmony and enhance both current and future potential to meet human needs and aspirations" [9] (p. 43). Social aspects—human needs and resources—play a major role in this definition [10].

Opoku and Ahmed understood sustainable development as "the adjustment of human behavior to address the needs of the present, without compromising the ability of future generations to meet their own needs" [11] (p. 141). Thus, they focused not so much on human needs as on patterns of human behavior [10], so this definition clearly refers to culture.

The three pillars of sustainable development are the economic, ecological and social pillars. It is worth emphasizing that, according to Cruz and Marques, to assess sustainable development, these three perspectives-economic, environmental and social-are necessary, but not sufficient. Governance and assets (technical) are important aspects. Governance is not an end in itself-it plays an instrumental function in relation to the other three perspectives, but it is also necessary to sustain the three pillars of sustainable development [5]. Good governance requires political responsibility, the rule of law, transparency and the involvement of citizens and all stakeholders in achieving sustainable development [12]. Effective governance is a fundamental condition for the sustainable development [13]. 
Having the assets (including infrastructure), which include aspects related to system performance, durability, reliability, flexibility and adaptability, allows for investing in sustainable development, as well as appropriate asset management, which enables achieving sustainable development goals, is another dimension allowing for the global assessment of sustainable development, but also efficiency in each of the individual dimensions [3].

Considering the above definitions, the concept of sustainable development is a kind of cultural order, i.e., a rational order [6] initiated by man. In addition, it is also a stage in the history of society of the transition from obtaining short-term profits towards economic efficiency, but also environmental, social and government-related performance. This last component also includes citizenship, values and ethical principles [14]. Therefore, it is a way of thinking and acting-a process through which people and organizations modify their behavior and customs. Accordingly, culture expresses itself through the concept of sustainable development, which is part of culture. Thus, culture is a more general concept in relation to sustainable development.

The above considerations correlate with one of the roles that culture plays in sustainable development according to Soini and Birkeland [15]. They proposed three roles that culture plays in relation to sustainable development. The first role is culture in sustainability-culture as capital, where it is one of the elements of sustainable development alongside economic, environmental and social. It is protection and preservation of cultural capital—art, heritage and knowledge. The second role is culture for sustainability-culture as a way of life. Culture is a condition and resource for sustainable development. It is a central category that affects all three dimensions of sustainable development: economic, ecological and social. The third role of culture as sustainability—culture as a semiosis. Culture is the foundation of the overarching category of sustainable development. Sustainable development is embedded in culture [16].

The relationship between culture and sustainable development is multifaceted. Culture drivers are factors that are rooted in culture and can be generated by culture and inspire changes. They are activators and motivators, thanks to which they become the driving force of sustainable development. Cultural drivers are a link that connects citizens, contributes to social cohesion, and also mean that individual areas of human life (economic, ecological, social, governance) can be a more humane and integrating society, ensuring a better quality of life [17].

Cultural drivers that affect sustainable development can be divided into material, immaterial and emerging [18]. The material factors include cultural heritage understood as human products: art, science, cultural landscape. Immaterial factors include tradition, identity, values, cultural diversity, spirituality, and aesthetics. Emerging cultural factors include tools and skills needed to understand and transform the world towards sustainable development-literacy, creativity, critical knowledge, sense of place, empathy, trust, respect and recognition [18]. In addition, developed civil society or equality can be potential socio-cultural factors supporting sustainable development.

Public policies, especially cultural policies, are also important cultural drivers affecting sustainable development. Culture development strategies are created by public administration at various levels. In Poland, implementing the idea of sustainable development through culture, enshrined in various types of strategies, consists of securing infrastructure, and diversifying the cultural offer, including ensuring the diversity of entities carrying out cultural activities, access to the cultural offer, and cultural education, supporting artistic (professional and amateur) activities, promoting the cultural offer and heritage of the regions, and increasing tourist attractiveness [19] (pp. 176-177). Various forms of revitalization are also gaining significance: revitalization through culture, the use of buildings and projects related to art to redefine a given area and attract other activities; cultural revitalization, the inclusion of a lifestyle including participation in culture in the strategy of a given area; a combination of culture and revitalization-culture is associated with the strategy but is not an integral part of it; and revitalization through artists, with the creation of new art studios and galleries, which affects the popularity of the place $[19,20]$. 
Thus, the cultural sector is also seen as a motor for economic development (cultural economy), but also as a tool for alleviating poverty. Cultural heritage, cultural and creative industries, cultural infrastructure and cultural tourism can all contribute to generating profits [21].

In addition, non-monetary benefits of cultural factors include increasing social integration, rooting, innovation, the use of local resources, knowledge, and increasing social capital. Cultural factors affect individual behavior and change consumption patterns, as well as the awareness of respect for the natural environment and its proper management. Culture transforms existing development approaches, significantly enriches development debates and contributes to the adequate and sustainable satisfaction of people's needs. It emphasizes human rights, including marginalized groups, respect for diversity and cultural heritage, but also the environment, thus encouraging intercultural dialogue. In this way, culture contributes to the optimal achievement of the goals of sustainable development [21].

\subsection{Living Labs}

While reviewing the literature on living labs, it was found that although this concept is becoming a promising methodology for social research, it is still in an early stage of development [22-26]. This concept originates from Professor William Mitchell at Massachusetts Institute of Technology (MIT), who initially used it to observe the living patterns of users in smart/future homes. The basic idea was to include the users in the value-creation process in real-life settings. The real people were observed in their usage of emerging technologies in the setting of a real home for several days or weeks [22].

According to Coorevits et al., along with the digital revolution nowadays, we can observe an increased tendency to extend the research beyond the limitations of closed laboratories towards the highly dynamic environment of "real life". Taking into account that people tailor their behavior to the setting they are in, products can be tested much better in real settings than in laboratory settings [27] (p. 40). Several authors pointed out the emerging trend of tailoring a living lab concept in wider use to enhance research, innovation, inclusion, usefulness and usability of technology and its applications in the society. They emphasize a pressing need for future research on living lab processes and methods $[22,23,25,28]$.

When looking for the definition of a living lab, it is not difficult to come across different ways of understanding this concept, which put emphasis on its various aspects. As Leminen rightly noted, "the term "living lab" is at risk of becoming a buzzword in the innovation domain because it lacks a consistent or commonly accepted definition" [29] (p. 29). Building on numerous studies, living labs can be regarded as long-term environments for open innovation that enable experimentation with real users in real contexts $[23,26,30,31]$. Two main directions in considering living labs are moving towards an emerging approach or methodology to innovation or an infrastructure that enable user-driven innovation practices $[22,23,26,27,30]$.

Dekker et al. pointed to living labs as a distinctive research and design methodology for co-creating innovation with the involvement of its stakeholders [26] (p. 9). Veeckman et al. presented a living lab as an emerging open innovation approach that involves multiple stakeholders (including users) to co-create value that eventually leads to innovation. It delivers a new way of structuring research through validation and testing in real-life contexts [30] (p. 6). According to Coorevits et al., "within innovation research and, more specifically, living lab projects, a crucial component is to test an innovation in a real-life context with potential end users. Such a field test can validate assumptions by combining insights on behavior and attitudes towards the innovation" [27] (p. 40). Schuurman et al. wrote about living labs as a structured approach to open innovation. They described the living lab approach as a five-phase methodology including: (i) contextualization, (ii) selection, (iii) concretization, (iv) implementation, and (v) feedback. Although it resembles a quasi-experimental design (with a pre-test, a real-life intervention, and a post-test), the methodological basis of these five phases remains still unexplored [32] (p. 8).

The concept of living labs was also presented as a socio-technical infrastructure to support user-centric and often open innovation processes [28,31,33]. According to Romero Herrera, such 
labs deliver collaborative platforms for professionals from different disciplines to work together with future users and public and private stakeholders to generate solutions that are rooted in the settings of daily life practices. The users play an active role in generating and applying contextualized practice-based knowledge in innovation processes [28]. Hasselkuß et al. presented living labs as combined lab-household systems that enable researchers to observe users and value chain-related actors in real practices within innovation processes. As they noted, "the LivingLab infrastructure provides means to observe practices involving technical artefacts and opportunities for users to experiment with such practices, learn and appropriate them in the process of everyday use" [33] (p. 24). Leminen showed living labs as environments in which user experiences reveal future directions of product development. As networks composed of heterogeneous actors, resources and activities, living labs offer a research "think-tank" and collaborative development platform to help applying user-driven innovation practices and support innovation at all phases of the lifecycle [31] (p. 7).

While studying the literature on living labs, the concept of a sustainability living lab was also revealed [28,33-37]. Romero Herrera presented a sustainability living lab as a socio-technical infrastructure for sustainable innovations to emerge, be implemented and tested together with potential users [28] (p. 10). Hasselkuß et al. pointed to living labs as a methodology of research on social practices and their changes related to more sustainable production and consumption [33]. As they claimed, "for change to take place, a break of on-going sense-making in practices must occur or can be induced by certain events or governance strategies" [33] (p. 31). Therefore, they conceptualized the sustainable living lab approach referred to social practice theory as a methodology of research on environmental behavior and awareness, and design sustainable product-service-systems around the home. Such infrastructure can provide an adequate setting for research and real-life experiments with transformational products and practices that may disturb existing routines [33].

Romero Herrera pointed out three elements which characterize sustainability living labs as user-centric processes [28] (p. 10):

- The practices observed are situated in real-life and realistic settings,

- The behaviors and experiences of daily life practices are focused,

- The technical, social and temporal dimensions of practices are approached in large scale and longitudinal setups.

Hence, as Dekker et al. claimed, living labs are distinctive not only by being situated in a real-life context, but also by putting more emphasis on iterative ways of learning-by-doing and being less focused on developing a common idea of a problem and solution. Comparing with action research, living labs give a more prominent role for the users in the evaluation of the product or service. Hence, this is a promising methodology for research into public sphere problems, which shows potential for generating actionable and situated knowledge on real-life problems [26] (p. 9). Leminen et al. put emphasis on living labs as networks that support creating innovations that better meet user needs. They can be physical or virtual realities in which stakeholders create public-private-people partnerships of firms, public agencies, universities, institutes, and users; living labs help to facilitate collaboration for the creation, prototyping, validating, and testing of new technologies, services, products, and systems in real-life contexts [31].

According to Baedeker et al., households and the interaction within the production and consumption systems are often the "black box" on the demand side. Hence, the role of living labs is to give the possibility of using a flexible socio-technical framework for analyzing the production-consumption system interaction. To optimize the production-consumption systems, the conditions of the test bed need to be configured based upon the investigated social context. Thus, people and their practices need to be analyzed in their real social context and day-to-day situations. The sustainable living lab design is necessary to combine and integrate a technological-socioeconomic approach to interactively develop technological and social innovations to enable the optimized interaction of production and consumption [37] (p. 42). 


\section{Materials and Methods}

While reviewing the worldwide literature, the significant lack of research on sustainability laboratories focused on studying the impact of cultural factors on sustainable development was found. Consequently, research efforts were aimed at building the concept of a sustainability innovation lab focused on studying the impact of cultural factors on sustainable practices and transformational products leading to new patterns and forms of more sustainable social relationships.

The research was carried out with the use of the conceptual research framework based on analyzing existing knowledge on cognitive processes occurring within living laboratories and their interpretation in the light of the knowledge about the relationship between culture and sustainable development processes. The existing knowledge was the source of reasoning leading us to solve the scientific problem. The key in such a research framework is the researcher's experience built on in-depth understanding of the studied issues and prevailing theoretical findings that allow them to conduct thought experiments.

The framework of the conducted research was based mainly on the assumptions of problematization as a way of reaching scientific problems for building a theory [38]. It included three research steps as follows.

In the first step, in accordance with the assumptions of problematization, the research goal was formulated and the basic assumptions in the current manner of describing and explaining the relationship between cultural factors and sustainable development were identified. This showed the reciprocal impact between culture and sustainable development as a problem that is worth further research and seeking new research opportunities for it. The results of this analysis are concisely presented in the previous section and in Sections 4 and 5 as the basis to build, justify and discuss the proposed model.

In the next step, the concept of the living lab was analyzed, going deeper to the level of basic assumptions of the concept so that it could be comprehensively understood to adapt to other problems. The results of this analysis are succinctly presented in the previous section and in Section 4, serving directly to build and justify the proposed model.

In the third step, a creative adaptation of the living lab concept to the study on the cultural drivers of sustainable development was made. Creative adaptation should be understood as the use of novel combinations of existing and new elements within the novel thought structure with coherent assumptions, which would support the creation of a new coherent model. The new concept would have at this point the status of a hypothesis rather than a confirmed theory. Hence, as a result of this step, a novel model of sustainability living lab as a framework for future research was created, under which it can be potentially corroborated (in the sense given to the term by Popper). This justifies calling such a study conceptual, as it leads to a new concept/model as a framework for future research.

Such experiments are a device to perform an intentional, structured process of intellectual deliberation in order to speculate about potential antecedents or consequences of specifiable things, phenomena or processes [39] (p. 150). They allow us to better assess the coherency of developed knowledge with the adopted assumptions and existing theoretical findings, and some grounded knowledge on the practices and rules that govern the empirical world within a specifiable problem domain; and therefore better determine the scientific value of developed hypotheses before undertaking extensive research in order to test them empirically. Developing such a hypothetical scenario allows us to better understand the things, phenomena and processes studied, and their properties, and the relationships between them. In such research, new knowledge arises in a complex and mostly implicit reasoning process, involving analysis and abstraction of the current knowledge, challenging the assumptions in existing theories [38] and reframing the context to create a new synthesis based on in-depth insight that is used to interpret and explain (theoretically) observed facts. 


\section{Research Dimensions}

The research undertaken is ultimately aimed at developing the dual process of both inquiry and introducing sustainable innovation on which the proposed sustainability living lab is based. In this section, the results of the initial phase of undertaken considerations are presented. They include mainly the outline of such a process within a broader conceptual framework, which is depicted in this paper. Sustainability living lab can be interpreted as a kind of real-life ecosystem for inquiry processes that lead to creating and experimenting with novel ideas and converting them into solutions to serious social problems (Figure 1). The undertaken considerations were based on the assumption that social behavior is tailored to its setting [27] (p. 40). Hence, such a laboratory is expected to offer a socio-technical infrastructure for sustainable innovations to emerge, be implemented and tested with and by potential users [28] (p. 10) and an appropriate methodology to research and design these processes in real-life settings.

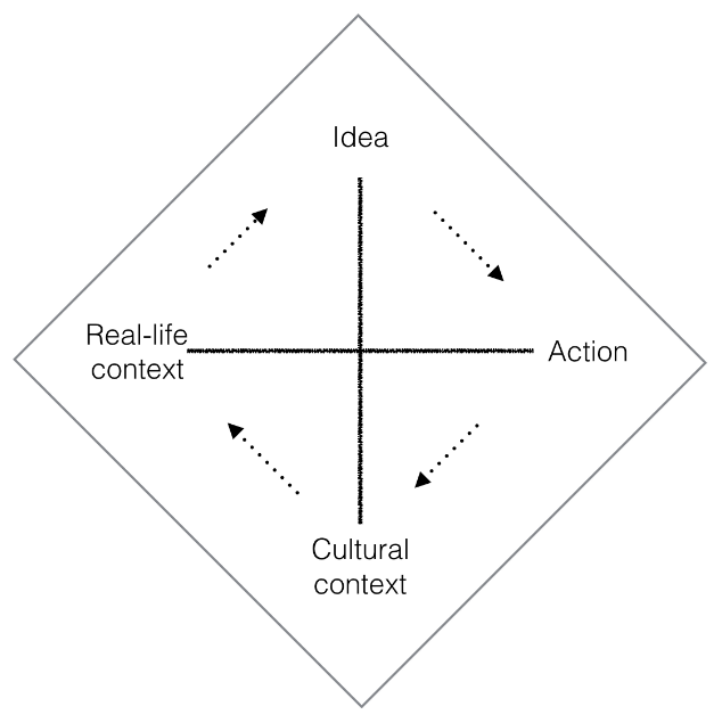

Figure 1. The model of sustainability living lab. Source: Own elaboration.

While innovation ecosystems are usually defined as platforms or hubs connecting technology companies, universities, startup environments, investors, central and local administration and other parties participating in or supporting the development of innovative companies in a country, region or within an organization [40], they can also be considered as the set of activities along the innovation processes and their drivers within and around the offered system solutions [41]. Among these drivers, particular attention was paid to cultural factors in the presented model (Figure 1).

The proposed model of sustainability living lab is represented schematically in Figure 1. This figure includes four components: the cultural context, the real-life context, dimension of the idea (the sphere of ideas) and the dimension of action (the area of actions), and the relationships between them. These components and relationships, along with the explanation of the overall logic and dynamics of this model, are explained in the following paragraphs.

This model is built on the analogy of a biological ecosystem. In a biological ecosystem, all living organisms in an area and its physical environment are functioning together as one unit [42]. While Jackson claimed that innovation ecosystems shape the economic relationships that are formed between actors or entities whose goal is to enable technology development and innovation [42], sustainable living labs should take into account the contribution of cultural drivers in these relationships and the broad cultural context (also in terms of defining the values and goals of economic development).

According to Jackson, two distinct economies coexist within innovation ecosystems: the research economy, driven by fundamental research, and the commercial economy, driven by the marketplace expectations [42]. By this analogy, in the sustainability living lab, two distinct logics of action coexist: 
the logic of research and the logic of designing and introducing novel sustainable solutions. Thus, as was said before, the process within the proposed sustainability living lab is dual in nature. It includes the research dimension and the dimension of introducing innovation, which are entwined with each other and inseparable. This results from the adopted assumption that the study of the impact of cultural factors on sustainable development should take place in real-life settings. This results also from the dual nature of culture, which is no longer treated as an autonomous sphere, and is living and associated with the action through which it can be shaped [43] (pp. 34-35). Hence, the proposed model of the lab reflects this real dual process and its components, which include: cultural context, real-life context, ideas and actions, and the relationship between them.

The cultural context is a kind of "toolbox" that is considered as a set of resources that are necessary for action in specific situations. As Sztompka notes, working people derive values from culture to set their goals, norms to specify the means of action, symbols to give them meaning, codes to express their cognitive content, frames to organize individual elements, and rituals to ensure their continuity and succession. In short, culture provides action with axiological, normative and cognitive orientation [43] (p. 34).

The real-life context identifies the real situation including: (1) a real problem to solve or (2) an opportunity to seize. Including this dimension in the model results from the assumption that people tailor their behavior to the setting they are in. Hence, according to Coorevits, the research needs to extend beyond the limitations of the closed laboratories towards the highly dynamic environment of real life [27] (p. 40).

The dimension of idea presents what we are looking for to reshape established patterns of activities and new ideas to solve problems and trigger changes. Novel ideas appear as: (1) the response to the circumstances of the situation, or (2) the imagined result of the change being sought by social actors. This dimension is often hidden in action, rarely explicit.

The dimension of action identifies observable actions taken by specific people in real everyday situations. Being observable means that they can be examined in the proposed laboratory. They can be examined only within the context in which they occur, taking into account that the context of the action is largely perceived by actors in a subjective way, which makes it difficult to study. Hence its direct observation by an external observer is not sufficient.

Assuming that a sustainability living lab ecosystem is a living environment (a community of living organisms within the nonliving components of their environment), it can afford research processes that can root designed solutions not only in real-life settings but also in a broad cultural context. Thus, such research requires building the entire ecosystem by fostering eligible processes of inquiry. In the presented model, it is assumed that the dotted lines indicate cognitive-behavioral cycles taking place in subsequent iterations: (1) from the assessment of the situation, (2) through emerging new ideas and (3) their performance in action, to (4) reinforcement or changing in the area of cultural patterns. We assume that culture, on the one hand, provides resources for action, and on the other hand, our actions can shape it creatively. While the problem to which the new idea responds is always embedded in a particular situation, the context of culture is extremely important for assessing the situation. It provides tools for its description, interpretation and evaluation (i.e., values, norms, standards, symbols, codes, frames).

The horizontal and vertical solid lines connect in turn (1) the real-life context and the area of action, and (2) the cultural context and the area of idea. They indicate some kind of tension between those areas that drive the cycle described above (marked the dotted lines). The first tension is in the horizontal dimension between the way of reading the situation and established patterns of activities in a certain domain. The other one is in a vertical dimension between resources provided by culture and new ideas that are born as a result of the response to the situational context.

If the established patterns of social practices do not keep up with the changes in real life, the tension arises and it can trigger the desire to search for new ideas, which starts the first phase of the cycle. If culture does not provide the resources necessary to implement these new ideas in the context 
of a common situation (and earlier its shared understanding), another type of tension may arise- on the line: the cultural context and the novel ideas. This tension can be reduced by (1) giving up the new ideas and submission to the cultural pressure or (2) strengthening the willingness to act in the direction of seeking opportunities for cultural change (giving the action a broader cultural dimension). In the latter case, the action will no longer be just a response to situational necessity (seeking an ad hoc solution), but it will be a lever for wider socio-cultural changes.

As previously mentioned, although the sustainability living lab is expected to offer a socio-technical infrastructure for sustainable innovations to emerge, its basis is above all methodological. Hence, the proposed operational model of such a laboratory does not reflect the traditionally understood laboratory (as an infrastructure), but its processes between the cultural context and the area of action taking place in real-life settings. The model, used to describe how social actors behave in specific situations embedded in a specific cultural context, was designed to constitute a framework of the sustainability living lab presumed as a methodological approach to study the impact of cultural drivers on sustainable development, including the cultural drivers of sustainable practices and transformational products and innovation.

The proposed model is justified by the current research findings from the literature, which are concisely explained in Section 2 and the above paragraphs of this section. Taking into account that the model is a creative adaptation of the assumptions of the living lab concept to study on the cultural drivers of sustainable development, three arguments justifying its construction can be indicated.

First, the need to look for new research opportunities and the problematization of the scientific problem regarding the cultural drivers of sustainable development arises from the reciprocal impact of culture and sustainable practices, and the dual nature of culture. Secondly, these assumptions about the nature of culture and its relationship to sustainable development combined with the fact that people tailor their behavior to the setting they are in are an argument for conducting research which extends beyond the limitations of closed laboratories towards real-life contexts [27].

Third, the deconstruction of the living lab approach based on the available literature points to the unique structure and dynamics of this approach [30,32,44,45]. Schuurman et al. indicated five different phases of such a project: (i) contextualization, (ii) selection, (iii) concretization, (iv) implementation, and (v) feedback [32] (p. 8). For the justification of the proposed model, contextualization deserves special attention. This strong dependence of the living lab processes on the context of action justifies the need to take into account the above-mentioned knowledge about (1) the reciprocal relationship between culture context and sustainable practices, and (2) the influence of the situational context associated with the impact of the dynamics of real-life environment (as explained in Section 2).

In addition, as a research framework that could be corroborated in future empirical research, the proposed model still has at this point the status of a hypothesis rather than a confirmed theory. However, the model shows good potential for research into cultural drivers of social development. Although most of its components and the relationship between them have been described in the literature, their combination with new elements as a coherent model within the existing assumptions is a distinctive research approach, which takes into account the structure and dynamics of cognitive and behavioral processes occurring as part of innovations for sustainable development within a broader cultural context.

\section{Discussion}

The theory-forming nature of the study presented in the paper requires a certain logic of reasoning and deliberation, different from empirical study, going from presenting the state of knowledge and adopted assumptions through conducting inferences leading to building the presented model, and placing it in a broad theoretical context. Scientific discussion is thereby present throughout the entire deliberation process, and the discussion of the results is necessarily found in part in the previous section. The following discussion aims to show the significance of the presented results against the background of a wider context, which will allow a better understanding of the nature of the relationship 
between culture and sustainable development, as well as culture and social practices and activities that can be studied in real-life settings within the proposed sustainability living labs.

In the context of sustainable development, which aims to care for current and future generations, three types of capital are emphasized: economic, human and natural. This lack of institutionalization of culture, such as the aspect of sustainable development, was primarily due to the lack of a definition of culture as a separate category. In addition, culture was not systematically included in policies, practices or assessments compared to the ecological, economic and social dimensions of sustainable development [15]. Measuring the impact of culture on sustainable development was an additional difficulty [15]. In this connection, the question arises: why should culture be examined in the context of sustainable development? Undoubtedly, culture is a key element of the concept of sustainable development, and the challenge is to understand the relationship between culture and sustainable development. Sustainable development is an integrated whole when it includes, next to the economic dimension, the ecological and social cultural dimensions as well. Achieving balance in other dimensions is impossible without a cultural component. The use of sustainable cultural development minimizes the excessive exploitation of natural resources, and also affects the appropriate management of these resources and transforms the landscape. It strengthens economic capital by generating revenues from the cultural industry, cultural heritage or cultural tourism, and creates jobs. In the social dimension, culture promotes the values of social justice and environmental responsibility, becoming a builder of social bonds [10]. Sustainable development is based on two principles formulated by The World Commission on Environment and Development in 1988: "1. Harmony between human beings and nature (respect for the planet's "ecological limits"); 2. Harmony among human beings (i.e., social cohesion)" [46] (p. 8).

Achieving harmony is possible through the functions implemented by culture; not only the pragmatic function that brings economic benefits, but above all the normative and axiological function-patterns, ideals, desirable states of affairs, and value systems. Autotelic experiencing and feeling of values contributes to the functioning of the community (integrating communities, crystallizing social identities) and to the well-being of individuals [47] (p. 11).

The concept of sustainable development is embedded in culture, and therefore culture determines sustainable development because we draw resources from it, but also provides a source of inspiration to take new actions.

Culture is universalistic - cultures intertwine [48], and hence the concept of sustainable development can be implemented in many countries similarly. However, cultures also constitute a closed system, which is characterized by impenetrability, impassability, coherence [48]. That is why the question arises not only about differences related to the implementation of the concept of sustainable development in individual countries and regions, and about the multiplicity of perspectives for sustainable development, but also about the existence of alternative paradigms for sustainable development.

Culture is stability on the one hand, and changeability and continuous evolution on the other-a manifestation of cultural creativity [48]. The concept of sustainable development requires innovative solutions. Living labs provide conditions for research into everyday, innovative practice. They facilitate adaptation to changes because they contribute to innovation of stakeholders. Thanks to the living labs method, users can test different types of solutions in a real context. Living labs are not only an environment that organizes the participation of users in innovative processes, but also a methodology. Thus, researchers are able to discover silent, experimental knowledge that can be further used [49]. The living labs method makes it possible to design or redesign our lives by engaging our ability to reflect on different types of reality [50]. One cannot forget that our view of reality conditions our actions [50].

The sustainability living lab focuses on ways to improve our lives in a more sustainable, efficient and comfortable direction. It provides more sustainable design options, arranging our living environment regarding uncertainty or potential unexpected events, including improvisation and exchange aspects, 
as well as gaining joint experience [51]. In other words, sustainability living labs support innovation in sustainable lifestyles, products and services offered; for example, building houses or other buildings made of materials that use as little as possible non-reproducible resources, with renewable energy [51]. In this way, we not only maintain a balance between our needs and the resources of the natural environment, but also change our behavior patterns. Indispensable in sustainability labs is a constructive contribution to the sustainable development of various communities in order to limit short-sighted, non-holistic perspectives that occur within individual competences [52].

The model of sustainability living labs presented in this article draws attention to cultural factors and emphasizes their role as an important aspect of sustainable development (culture in sustainability development, culture for sustainability development, culture as sustainability development). This is not a common practice, especially in public policies. Taking this factor into account allows us to gain knowledge as to why certain ideas are born and implemented, while others are not, and what cultural factors and to what extent they change the reality or strengthen the existing one and to what extent they contribute to the development of sustainability. The use of this model also allows us to learn and identify challenges related to sustainability development in a given cultural circle.

The sustainability living lab is a tool to increase the involvement of various stakeholders and plan the implementation of the concept of sustainability development in accordance with the needs of the community. It allows us to describe similar or identical phenomena through various cultural contexts [53]. This gives us the chance to increase the ability to adapt to a sustainable future in a culture, as well as to choose factors that are transcultural factors and are useable and applicable for people [53].

Considering that the proposed model is theoretical in nature and it has at this point the status of a hypothesis rather than a confirmed theory, the discussion is completed by highlighting some limitations of the work and the future research directions.

The first limitation of this work is related to the subjectivity of the proposed approach. This approach would be included into qualitative methods (interpretative) methods. The results of empirical research that could be obtained as a result of the use of the proposed research framework will be not only interpretative, but also subjective. These results would strongly depend on the subjective perception of the cultural and situational context by those involved in the research (both subjects and researchers). Even if we assume that an external or objective truth on cultural drivers of sustainable development exists, it will be hardly possible to obtain this knowledge by using the proposed model.

The proposed approach is also limited in terms of formulating generalizations and potentially building the theory on the cultural drivers of sustainable development. It is related to two properties of the cultural context. First, the dual nature of culture means that the studied social activities and practices have an impact on the culture from which they draw resources to act. Hence, the research within the framework of the sustainability living lab would affect not only the situational but also the cultural context (especially in the long run), which may hinder attempts to create generalizations or build the theory on the relationship between culture and sustainable development. Secondly, it is difficult (if at all possible) to create some standards or procedures for describing and measuring the cultural context to be able to describe and explain (and perhaps also forecast) the impact of cultural factors on sustainable development practices, especially taking into account the impact of the situational context. Therefore, it can be difficult to go beyond idiographic research limited usually to case reports.

Taking into account the theoretical nature of the proposed model, the future research concerns empirical studies with use of the proposed approach to test its empirical value. In the next research step, it is necessary to operationalize the proposed approach, taking into account especially: (1) decisions regarding concepts and their definitions (especially those related to individual components of the model: the cultural context, the real-life context, the sphere of idea and the area of action), (2) defining related indicators and variables, (3) the indication of the population and the contexts in which the research will be carried out, (4) decision on the research methods and techniques used to collect empirical data, and (5) the method of analysis of the obtained empirical material. 


\section{Conclusions}

Cultural drivers are key to the concept of sustainable development although often overlooked in many scientific studies. Sustainable development and, consequently, a balanced life means maintaining an adequate quality of life. The concept of sustainable development was born out of the need to care for nature and man. Current culture is dominated by thinking in terms of having. It carries with it fears, antagonisms and rivalries that cause the expansive exploitation of natural and human resources, thus causing huge inequalities in society. The concept of sustainable development using the sustainability living labs method can contribute to a long-term change in relations between individuals-using the E. Fromm language-changing modus having to modus being [54] by changing existing dominant cultural patterns.

It is necessary to take into account cultural diversity, which affects the multiplicity of perspectives or alternative approaches to sustainable development, and taking into account the criterion of diversity, it is necessary to analyze development concepts, including sustainable development. Hence the proposed model of the sustainability living lab delivers the methodological proposal for the research on the cultural drivers of sustainable development. Assuming that the studied processes based on human behavior are tailored to their setting, such a laboratory is considered both as (1) a socio-technical infrastructure for sustainable innovations to emerge, be implemented and tested with and by potential users and (2) an appropriate methodology to research and design these processes in real-life settings.

The latter aspect constitutes the basis of such a laboratory that is rooted in the highly dynamic environment of real life. Although the sustainability living lab is also expected to offer a socio-technical infrastructure for developing sustainable innovations, its basis is a special methodology to research and design these processes in real-life settings with special emphasis on cultural drivers and a broad cultural context, and its consequences for defining the values and goals of economic development. The proposed operational model of such a laboratory thereupon is focused on the processes between the cultural context and the area of action taking place in real-life setting.

The research undertaken is ultimately aimed at developing the dual process of both inquiry and introducing sustainable innovation on which the proposed sustainability living lab is based. In this section, the results of the initial phase of undertaken considerations are presented. They include mainly the outline of such a process within a broader conceptual framework, which was depicted in this paper. The sustainability living lab is considered as a kind of real-life ecosystem for research and creative processes, which, intertwining these processes, leads to creating and experimenting with novel ideas and converting them into solutions to serious social problems.

Since this study was theoretical, without further empirical research that could corroborate the proposed model, it has at this stage the status of a hypothesis rather than a confirmed theory. Hence, it has some limitations, which have been comprehensively explained in the previous section. Among them should be indicated: (1) the subjective nature of the knowledge that could be obtained using the proposed approach (2) the limited possibility for formulating generalizations because of the dual nature of culture and associated difficulties in creating some standards or procedures for describing and measuring the cultural context.

The limitations of this study may indicate some future research directions. Considering the theoretical nature of the proposed model, the future research concerns empirical studies with the use of the proposed approach to corroborate it by testing its usability as a research method. This requires further operationalization of the model by defining the concepts, and related variables and indicators, and decisions on the research methods and techniques used to collect and analyze empirical data.

This research also offers some implications for decision makers. The proposed approach indicates the importance of the cultural context for sustainable development, which could be an important factor taken into account when formulating public policies and managerial decisions, especially in the field of: (1) the recognition and use of cultural drivers as one of the main drivers of sustainable development, (2) the use of novel approaches (i.e., living labs) for development of sustainable practices and innovations, (3) developing innovative solutions and their rapid adaptation through the 
participation of members of society in solving problems, (4) satisfying the diverse needs of society in a way adapted to their cultural patterns and according to their expectations, and (5) using the proposed approach as a model for introducing public changes.

Author Contributions: Conceptualization: G.B., A.B.; methodology: G.B., A.B.; investigation: G.B., A.B.; resources: G.B., A.B., data curation: G.B., A.B.; writing—original draft preparation: G.B., A.B.; writing—review and editing: G.B., A.B. All authors have read and agreed to the published version of the manuscript.

Funding: This research received no external funding.

Conflicts of Interest: The authors declare no conflict of interest.

\section{References}

1. Hawkes, J. The Fourth Pillar of Sustainability: Culture's Essential Role in Public Planning, Cultural Development, Network (Vic.); Common Ground: Melbourne, Australia, 2001.

2. James, P. Assessing Cultural Sustainability: Agenda 21 for Culture; UCLG: Barcelona, Spain, 2014.

3. Marques, R.; Cruz, N.; Pires, J. Measuring the sustainability of urban water services. Environ. Sci. Policy Elsevier 2015, 54, 142-151. [CrossRef]

4. Interreg Central Europe. The Transformative Power of Industrial Culture. Available online: https://www.interregcentral.eu/Content.Node/InduCult2.0/Transnational.pdf (accessed on 29 May 2020).

5. Cruz, N.F.; Marquez, R.C. Scorecards for sustainable local governments. Cities 2014, 39, 165-170.

6. Daszkiewicz, W. Podstawowe rozumienie kultury-ujęcie filozoficzne. Rocz. Kult. 2010, 1, 43-64.

7. Kłosowska, A. Kultura Masowa: Krytyka i Obrona; PWN: Warszawa, Poland, 2006.

8. Lusawa, R. Hans Carl von Carlowitz twórca pojẹcia "trwałości”. Rocz. Nauk. Wydziału Zarzadzania W Ciechanowie 2009, 1-2, 5-17.

9. Brundtland, G.H. Our Common Future: Report of the World Commission in Environment and Development; Oxford University Press: Oxford, UK, 1987.

10. Opoku, A. The role of culture in a sustainable build environment. In Sustainable Operations Management; Chiarini, A., Ed.; Springer: Basel, Switzerland, 2015; pp. 37-52.

11. Opoku, A.; Ahmed, V. Understanding sustainability: A view from intraorganizational leadership within UK construction organizations. Int. J. Archit. Eng. Constr. 2013, 2, 133-143.

12. Odugbesan, J.A.; Rjoub, H. Relationship among HIV/AIDS Prevalence, Human Capital, Good Governance, and Sustainable Development: Empirical Evidence from Sub-Saharan Africa. Sustainability 2019, 11, 1348. [CrossRef]

13. Anjos, F.A.; Kennel, J. Tourism, governance and sustainable development. Sustainability 2019, 11, 4257. [CrossRef]

14. Carter, C.E.; Rogers, D.S. A framework of sustainable supply chain management: Moving toward new theory. Int. J. Phys. Distrib. Logist. Manag. 2008, 38, 360-387. [CrossRef]

15. Soini, K.; Birkeland, I. Exploring the scientific discourse of cultural sustainability. Geoforum 2014, 51, 213-223. [CrossRef]

16. Soini, K.; Dessein, J. Culture-Sustainability Relation: Towards a Conceptual Framework. Sustainability 2016, 8, 167. [CrossRef]

17. Geatan, S.; Allam, Z. Culture as a driver for sustainable urban development. In Proceedings of the Conference: UIA Seoul World Architects Congress, Seoul, Korea, 3-10 September 2017.

18. Axelsson, R.; Angelstam, P.; Dagerman, E.; Teitelbaum, S.; Andersson, K.; Elbakidze, M.; Drotz, M.K. Social and Cultural Sustainability: Criteria, Indicators, Verifier Variables for Measurement and Maps for Visualization to Support Planning. Ambio 2013, 42, 215-228. [CrossRef] [PubMed]

19. Plebańczyk, K. Role kultury we współczesnych strategiach rozwoju zrównoważonego. Studia Ekon. Zesz. Nauk. Uniw. Ekon. W Katowicach 2018, 378, 163-181.

20. European Economic and Social Committee. Culture, Cities and Identity in Europe; European Economic and Social Committee: Brussels, Belgium, 2016.

21. UNESCO. Culture: A Driver and a Enabler of Sustainability Development; UNESCO: Paris, France, 2012. 
22. Eriksson, M.; Niitamo, V.P.; Kulkki, S. State-of-the-Art in Utilizing Living Labs Approach to User-Centric ICT Innovation-a European Approach; Center for Distance-spanning Technology, Lulea University of Technology Sweden: Lulea, Sweden, 2005.

23. Følstad, A. Living labs for innovation and development of information and communication technology: A literature review. Electron. J. Virtual Organ. Netw. 10 Spec. Living Labso 2008, 10, 100-131.

24. Klimowicz, M. Żywe Laboratoria jako innowacyjne narzędzie zarządzania miastami. In (Re)organizacja w Zarządzaniu Miastami w Polsce w Kontekście Wyzwań Rozwojowych; Wiktorska-Święcicka, A., Ed.; Oficyna Wydawnicza ATUT: Wrocław, Poland, 2015; pp. 186-197.

25. Keyson, D.V.; Guerra-Santin, O.; Lockton, D. Living Labs. Design and Assessment of Sustainable Living; Springer: Delft, The Netherlands, 2017.

26. Dekker, R.; Franco Contreras, J.; Meijer, A. The Living Lab as a Methodology for Public Administration Research: A Systematic Literature Review of its Applications in the Social Sciences. Int. J. Public Adm. 2019. Available online: https://www.tandfonline.com/doi/full/10.1080/01900692.2019.1668410 (accessed on 28 May 2020). [CrossRef]

27. Coorevits, L.; Georges, A.; Schuurman, D. A Framework for Field Testing in Living Lab Innovation Projects. Technol. Innov. Manag. Rev. 2018, 8, 40-50. [CrossRef]

28. Romero Herrera, N. The Emergence of Living Lab Methods. In Living Labs. Design and Assessment of Sustainable Living; Keyson, D.V., Ed.; Springer: Delft, The Netherlands, 2017; pp. 9-22.

29. Leminen, S.Q.A. What Are Living Labs? Technol. Innov. Manag. Rev. 2015, 5, 29-35. [CrossRef]

30. Veeckman, C.; Schuurman, D.; Leminen, S.; Westerlund, M. Linking living lab characteristics and their outcomes: Towards a conceptual framework. Technol. Innov. Manag. Rev. 2013, 3, 6-15. [CrossRef]

31. Leminen, S.; Westerlund, M.; Nyström, A.G. Living Labs as Open-Innovation Networks. Technol. Innov. Manag. Rev. 2012. Available online: https://timreview.ca/article/602 (accessed on 27 May 2020). [CrossRef]

32. Schuurman, D.; De Marez, L.; Ballon, P. The impact of living lab methodology on open innovation contributions and outcomes. Technol. Innov. Manag. Rev. 2016, 6, 7-16. [CrossRef]

33. Hasselkuß, M.; Baedeker, C.; Liedtke, C. Social practices as a main focus in living lab research. In Living Labs. Design and Assessment of Sustainable Living; Keyson, D.V., Ed.; Springer: Delft, The Netherland, 2017; pp. 23-34.

34. Welfens, M.J.; Liedtke, C.; Rohn, H.; Nordmann, J. Living Lab: Research and development of sustainable products and services through user-driven innovation in experimental-oriented environments. In Proceedings of the ERSCP-EMSU Conference Knowledge Collaboration and Learning for Sustainable Innovation, Delft, The Netherlands, 25-29 October 2010.

35. Liedtke, C.; Welfens, M.J.; Rohn, H.; Nordmann, J. Living Lab: User-Driven Innovation for Sustainability. Int. J. Sustain. High. Educ. 2012, 13, 106-118. [CrossRef]

36. Liedtke, C.; Baedeker, C.; Hasselkuß, M.; Rohn, H.; Grinewitschus, V. User-integrated innovation in Sustainable Living Labs: An experimental infrastructure for researching and developing sustainable product service systems. J. Clean. Prod. 2015, 97, 106-116. [CrossRef]

37. Baedeker, C.; Christa Liedtke, C.; Welfens, M.J. Green Economy as a Framework for Product-Service Systems Development: The Role of Sustainable Living Labs. In Living Labs. Design and Assessment of Sustainable Living; Keyson, D.W., Ed.; Springer: Delft, The Netherlands, 2017; pp. 35-52.

38. Alvesson, M.; Sandberg, J. Generating research questions through problematization. Acad. Manag. Rev. 2011, 36, 247-271.

39. Yeates, L.B. Thought Experimentation: A cognitive Approach. Graduate Diploma in Arts (By Research) Dissertation; University of New South Wales: Kensington, Australia, 2004.

40. Gawer, A.; Cusumano, M.A. Industry platforms and ecosystem innovation. J. Prod. Innov. Manag. 2014, 31, 417-433. [CrossRef]

41. Rohrbeck, R.; Hölzle, K.; Gemünden, H.G. Opening up for competitive advantage-How Deutsche Telekom creates an open innovation ecosystem. RD Manag. 2009, 39, 420-430. [CrossRef]

42. Jackson, D.J. What Is an Innovation Ecosystem? National Science Foundation: Arlington, VA, USA, 2011.

43. Sztompka, P. Zaufanie: Fundament Społeczeństwa; Wydawnictwo Znak: Kraków, Poland, 2007; pp. 34-35.

44. Bergvall-Kåreborn, B.; Eriksson, C.I.; Ståhlbröst, A.; Svensson, J. A milieu for innovation: Defining living labs. In Proceedings of the ISPIM Innovation Symposium, New York, NY, USA, 6-9 December 2009. 
45. Zurbriggen, C.; Lago, M.G. An experimental evaluation tool for the Public Innovation Lab of the Uruguayan government. Evid. Policy A J. Res. Debate Pract. 2019, 15, 437-451. [CrossRef]

46. Dallaire, G.; Colbert, F. Sustainable development and cultural policy: Do they make a happy marriage? Encact J. Cult. Manag. Policy 2012, 2, 6-11.

47. Sztompka, P. O pojęciu kultury raz jeszcze. Studia Socjol. 2019, 1, 7-23.

48. Hańderek, J. Pojęcia i definicje kultury. In Filozofia Kultury; Mróz, P., Ed.; Uniwersytet Jagielloński: Kraków, Poland, 2015; pp. 23-42.

49. Ballon, P.; Schuurman, D. Living Labs: Concepts, tools and cases. Info 2015, 17, 1-15. Available online: https://www.researchgate.net/publication/277950787_Living_labs_concepts_tools_and_cases (accessed on 13 May 2020). [CrossRef]

50. Ehrenfeld, J.R. Uncovering the roots of unsustainability. In Sustainability by Design; Ehrenfeld, J.R., Ed.; Yale University Press: New Haven, CT, USA; London, UK, 2008; pp. 22-35.

51. Timmeren van, A.; Keyson, D.V. Towards sustainable living. In Living Labs. Design and Assessment of Sustainable Living; Keyson, D.W., Ed.; Springer: Delft, The Netherlands, 2017; pp. 3-7.

52. Hagy, S.; Selberg, P.; Toubs, L.; Femenias, P. DARE2Build. In Living Labs. Design and Assessment of Sustainable Living; Keyson, D.W., Ed.; Springer: Delft, The Netherlands, 2017; pp. 103-113.

53. Filho, W.L.; Salvia, A.L.; Pretorius, R.W.; Brandli, L.L.; Manolas, E.; Alves, F.; Azeiterio, U.; Rogers, J.; Shiel, C.; De Paco, A. Universities as Living Labs for Sustainable Development; Springer: Cham, Switzerland, 2020; pp. 136-137.

54. Fromm, E. To Have or To Be? Harper and Row: New York, NY, USA, 1976.

(C) 2020 by the authors. Licensee MDPI, Basel, Switzerland. This article is an open access article distributed under the terms and conditions of the Creative Commons Attribution (CC BY) license (http://creativecommons.org/licenses/by/4.0/). 